\title{
Efficacy of endoluminal interventional therapy in diabetic peripheral arterial occlusive disease: a retrospective trial
}

\author{
Liang Xiao ${ }^{1 *}$, De-sheng Huang ${ }^{2}$, Jia-jie Tong ${ }^{1}$ and Jing Shen
}

\begin{abstract}
Background: The purpose of this study was to assess the efficacy of interventional therapy for peripheral arterial occlusive disease and the difference between diabetic patients and non-diabetic patients.

Methods: 139 consecutive patients between September 2006 and September 2010 who underwent percutaneous lower extremity revascularization for arterial lesions were divided into diabetes group $(n=62)$ and non-diabetes group $(n=77)$. Before intervention, rest ankle brachial indexes and three dimensional computed tomography angiography from abdominal aorta to tiptoe were performed. The interventional treatments included angioplasty with or without stenting. The clinical outcomes included rest ankle-brachial indexes, primary patency rates, secondary patency rates and limb-salvage rates for 6-month, 12-month, 24-month and 36-month after treatment. The primary and secondary patency rates of all interventions and the limb-salvage rates of the patients are illustrated by Kaplan-Meier curves and compared by log-rank analysis.
\end{abstract}

Results: The interventional operation success rates were $98.4 \%$ (61/62) in diabetes group and 100\% (77/77) in nondiabetes group. The re-interventional operation success rates were 85.7\% (18/21) in diabetes group and 76.9\% (20/ 26) in non-diabetes group. The mean value of ankle brachial indexes was significantly increased after intervention $(0.397 \pm 0.125$ versus $0.779 \pm 0.137, \mathrm{t}=-25.780, P<0.001)$ in diabetes group and $(0.406 \pm 0.101$ versus $0.786 \pm$ $0.121, \mathrm{t}=-37.221, P<0.001$ ) in non-diabetes group. Perioperative 30 -day mortality was $0 \%$. Major complications included groin hematoma in $7.2 \%$, and pseudoaneurysm formation 2.2\%. In diabetes group, 6, 12, 24, and 36month primary patency rates were $88.7 \% \pm 4.0 \%, 62.3 \% \pm 6.6 \%, 55.3 \% \pm 7.0 \%$, and $46.5 \% \pm 7.5 \%$; secondary patency rates were $93.5 \% \pm 3.1 \%, 82.3 \% \pm 5.1 \%, 70.8 \% \pm 6.5 \%$, and $65.7 \% \pm 7 \%$; limb-salvage rates were $95.2 \% \pm$ $2.7 \%, 87.7 \% \pm 4.4 \%, 85.5 \% \pm 4.8 \%$, and $81.9 \% \pm 5.8 \%$. In non-diabetes group, $6,12,24$, and 36 -month primary patency rates were $90.9 \% \pm 3.3 \%, 71.8 \% \pm 5.4 \%, 71.8 \% \pm 5.4 \%$, and $60.9 \% \pm 6.2 \%$; secondary patency rates were $96.1 \% \pm 2.2 \%, 91.6 \% \pm 3.3 \%, 82.7 \% \pm 4.8 \%$, and $71.8 \% \pm 6.2 \%$; limb-salvage rates were $97.4 \% \pm 1.8 \%, 94.4 \% \pm 2.7 \%$, $90.6 \% \pm 3.7 \%$, and $83.1 \% \pm 5.4 \%$. The differences between two groups were not significant $(P>0.05)$.

Conclusion: With a low risk of morbidity and mortality, the percutaneous revascularization accepted by patients does not affect ultimate necessary surgical revascularization and consequently should be considered as the preferred therapy for chronic lower extremity ischemia. The efficacy and prognosis of interventional therapy in diabetic patients is similar that in non-diabetic patients.

Keywords: Diabetic Angiopathy, Efficacy, Percutaneous Transluminal Angioplasty, Stents

\footnotetext{
* Correspondence: xiaoliangcmu@yahoo.com.cn

'Department of Radiology, the First Hospital of China Medical University, 155\# Nanjing North Road, Shenyang 110001, Liaoning, People's Republic of China

Full list of author information is available at the end of the article
}

\section{Ciomed Central}

(C) 2012 Xiao et al; licensee BioMed Central Ltd. This is an Open Access article distributed under the terms of the Creative Commons Attribution License (http://creativecommons.org/licenses/by/2.0), which permits unrestricted use, distribution, and reproduction in any medium, provided the original work is properly cited. 


\section{Introduction}

Diabetes is a common concomitant condition for the patients with peripheral arterial occlusive disease (PAOD) and is increasing in prevalence [1]. Diabetics with PAOD carry a considerably worse prognosis than those without diabetes [2]. They account for more than half in the non-traumatic lower limb amputations. 20\% of these patients with infected foot wounds ended up with some type of lower extremity amputation.

Previously, percutaneous lower extremity arterial revascularization was offered only to the patients who had contraindications to open surgical bypass or had used up all surgical options. In recent years, however, an increasing number of patients have undergone percutaneous intervention as a first-line therapy for arterial occlusive disease of the lower extremity [3]. Successful revascularization could reduce the rate of major amputation, improve the healing of foot ulcers and raise the quality of life in diabetic patients with PAOD. Furthermore, an increasing number of techniques for percutaneous therapy have become available, including laser angioplasty, drug eluting balloon, absorbable metal stent and rotational atherectomy [4-8], thereby expanding the range and type of lesions suitable for percutaneous treatment.

In the study we sought to evaluate lower extremity arterial interventional therapy feasibility, revascularization efficacy, complications and limb salvage rate in a population of consecutive diabetic patients and non-diabetic patients hospitalized for PAOD.

\section{Materials and methods}

A retrospective research of the institutional database was performed to identify 68 diabetic patients (diabetes group) and 80 non-diabetic patients (non-diabetes group) between September 2006 and September 2010 who underwent percutaneous revascularization for lower extremity arterial lesions (both stenoses and occlusions). After a complete description of the study to the patients, the written informed consent was obtained in accordance with National Health and Medical Research Council guidelines. The study has been approved by the Ethics Committee of Hospital. Before intervention, rest ankle brachial indexes (ABI) and three dimensional computed tomography angiography (3D-CTA) from abdominal aorta to tiptoe were performed in all patients. Indications for interventional procedure included debilitating claudication or limb-threatening ischemia and lower extremity arterial lesions found by 3D-CTA.

A contralateral femoral approach was used in the majority of patients while an ipsilateral antegrade femoral approach was only employed when isolated tibial arterial disease was anticipated from preoperative studies.
Interventional operations were performed through a $5 \mathrm{~F}$ or $6 \mathrm{~F}$ sheath (length 11-45 cm). Selective angiography was performed to localize lesions and measure the range of lesions by using $4 \mathrm{~F}$ or $5 \mathrm{~F}$ catheter. The decision to intervene was made after diagnostic angiography. Deciding whether to proceed with revascularization operation was based on the necessity of clinical symptoms instead of the extent of the collateralization. All patients were anticoagulated with intravenous unfraction heparin (5,000 units) before lesion being crossed.

Under monitoring with X-ray, lesions were crossed with either luminal or subintimal technique using hydrophilic guide wires $(0.035,0.018$ or 0.014 inch). Guide wires were supported using $4 \mathrm{~F}$ or $5 \mathrm{~F}$ angled catheter. Reentry into the arterial luminal space beyond the occlusive lesion was confirmed by angiography before further intervention. Percutaneous transluminal angioplasty (PTA) was performed with appropriately sized noncompliant balloons (2.5-8.0 mm diameter) for the treated vessel, with inflation times ranging from 60 to 180 seconds at 6 to 15 atmosphere of pressure. Stent was implanted selectively for $>30 \%$ residual stenosis or flow-limiting dissections. Re-examination angiography with evaluation of the extent of residual stenosis and distal runoff was performed after interventions. PTA success was defined as dilation of all arterial lesions with a residual stenosis of $\leq 20 \%$. Stent technical success was defined as a residual stenosis of $<20 \%$ after stent placement. All interventional procedures were performed under local anesthesia.

After arterial intervention, patients received $0.4 \mathrm{ml}$ low molecular heparin injection at twice daily for a week. Activated clotting times were not monitored. Aspirin $100 \mathrm{mg}$ was administered daily to all patients postoperatively unless contraindicated. For patients undergoing stent placement, a loading dose of Clopidogrel $300 \mathrm{mg}$ was administered in ward, followed by $75 \mathrm{mg} / \mathrm{d}$ for 1 year. ABI was obtained one week after the procedure.

Patients were evaluated postoperatively and then at 6month intervals by physical examination (pulses and presence or absence of claudication or rest pain) and by vascular laboratory exam (ABI and arterial duplex ultrasound). Patency was determined primarily by arterial duplex of the treated vessel and secondarily by $\mathrm{ABI}$ and clinical parameters. Loss of patency on arterial duplex was defined as the presence of an occlusion or a restenosis associated with a velocity ratio of greater than $4: 1$ (relative to the segment proximal to the treated region). Percutaneous treatment failure was defined as loss of patency by anatomic or hemodynamic measures without effective revascularization. During follow-up a patient was considered to lose patency if restenosis or occlusion was detected in any of the lesions treated. 
All analyses were conducted using the Statistical Package for Social Sciences, version 11.5 (SPSS). Continuous variables were described with summary statistics such as means and standard deviations. Categorical variables were described with frequencies and percentages. Student's $t$ test and chi square analysis were used as appropriate to evaluate between-group differences in baseline characteristics, and changes of ABI before and after primary intervention. Primary and secondary patency and limb salvage rates were computed by Kaplan-Meier survival curves and compared by log-rank analysis. The difference was considered statistically significant at $\mathrm{p}<$ 0.05 .

\section{Results}

148 patients were enrolled in the trial. 9 patients were withdrawn from the study because of lost in follow-up. This led to 139 (93.9\%) patients who were included in the study. The two groups did not differ significantly in demographic or clinical characteristics and baseline ABI (Table 1).

The mean values of ABI were significantly increased after primary intervention $(0.397 \pm 0.125$ versus $0.779 \pm$ $0.137, \mathrm{t}=-25.780, P<0.001)$ in diabetes group and $(0.406 \pm 0.101$ versus $0.786 \pm 0.121, \mathrm{t}=-37.221, P<$ $0.001)$ in non-diabetes group.

Primary and secondary patency rates for all interventions and limb-salvage rates for patients are illustrated by Kaplan-Meier curves (Figures 1, 2 and 3 and Table 2).

In diabetes group, 6, 12, 24, and 36-month primary patency rates were $88.7 \% \pm 4.0 \%, 62.3 \% \pm 6.6 \%, 55.3 \% \pm$ $7.0 \%$, and $46.5 \% \pm 7.5 \%$; whereas secondary patency rates were $93.5 \% \pm 3.1 \%, 82.3 \% \pm 5.1 \%, 70.8 \% \pm 6.5 \%$, and $65.7 \% \pm 7 \%$; limb-salvage rates were $95.2 \% \pm 2.7 \%$, $87.7 \% \pm 4.4 \%, 85.5 \% \pm 4.8 \%$, and $81.9 \% \pm 5.8 \%$. In nondiabetes group, $6,12,24$, and 36 -month primary patency rates were $90.9 \% \pm 3.3 \%, 71.8 \% \pm 5.4 \%, 71.8 \% \pm 5.4 \%$, and $60.9 \% \pm 6.2 \%$; secondary patency rates were $96.1 \%$ $\pm 2.2 \%, 91.6 \% \pm 3.3 \%, 82.7 \% \pm 4.8 \%$, and $71.8 \% \pm 6.2 \%$; limb-salvage rates were $97.4 \% \pm 1.8 \%, 94.4 \% \pm 2.7 \%$, $90.6 \% \pm 3.7 \%$, and $83.1 \% \pm 5.4 \%$. The differences between two groups were not significant $(P>0.05)$.

A total of 83 percutaneous interventions (32 PTA only, 51 PTA and Stent) included 62 primary interventions and 21 re-interventions were performed on 62 diabetic patients. 103 percutaneous interventions (39 PTA only, 64 PTA and Stent) included 77 primary interventions and 26 re-interventions were performed on 77 non-diabetic patients. All lesions were categorized by location: 58 were iliac lesions (23.5\%)(Figure 4), 112 were femoral lesions (45.3\%)(Figure 4), 42 were popliteal lesions (17.0\%)(Figure 5) and 35 were tibial lesions (14.2\%)(Figure 6). 6, 12, 24, and 36-month primary and secondary patency rates for different lesions in diabetes group and non-diabetes group are illustrated by KaplanMeier curves (Figures 7, 8, 9 and 10 and Tables 3 and $4)$.

Interventional operation success rate in diabetes group is $98.4 \%(61 / 62)$. In one patient with PAOD (1.6\%), there was failure to cross the total occlusion with a wire. The patient's condition was not worsened by the attempted intervention. The patient had successful distal bypass. Interventional operation success rate in non-diabetes group is $100 \%(77 / 77)$.

Table 1 Demographic and Clinical Characteristics of 139 patients Across Treatment Groups at Baseline

\begin{tabular}{|c|c|c|c|c|}
\hline Characteristics & $\begin{array}{l}\text { Diabetes group } \\
\quad(n=62)\end{array}$ & Non-diabetes group $(n=77)$ & $\begin{array}{c}\text { Test } \\
\text { Statistics }\end{array}$ & $\begin{array}{c}P \\
\text { Value }\end{array}$ \\
\hline Age(years) & $64.7 \pm 11.0$ & $65.2 \pm 9.8$ & -0.308 & 0.759 \\
\hline Male & $37(59.7 \%)$ & $49(63.6 \%)$ & 0.228 & 0.633 \\
\hline history of tobacco & $33(53.2 \%)$ & $45(58.4 \%)$ & 0.379 & 0.538 \\
\hline hypertension & $36(58.1 \%)$ & $53(68.8 \%)$ & 1.729 & 0.189 \\
\hline coronary artery disease & 19(30.6\%) & $21(27.3 \%)$ & 0.191 & 0.662 \\
\hline Treatment with insulin & $45(72.6 \%)$ & $0(0 \%)$ & $\begin{array}{l}\text { Fisher's } \\
\text { exact test }\end{array}$ & 0.000 \\
\hline Pre-operation ABI & $0.396 \pm 0.125$ & $0.406 \pm 0.101$ & 0.113 & 0.910 \\
\hline \multicolumn{5}{|l|}{ Lesion location } \\
\hline \|liac artery & $26(23.2 \%)$ & $32(23.7 \%)$ & 0.002 & 0.964 \\
\hline Femoral artery & $51(45.5 \%)$ & $61(45.2 \%)$ & 0.202 & 0.653 \\
\hline Popliteal artery & 19(17\%) & 23(17\%) & 0.010 & 0.921 \\
\hline Tibial artery & $16(14.3 \%)$ & $19(14.1 \%)$ & 0.023 & 0.879 \\
\hline \multicolumn{5}{|l|}{ Clinical symptom } \\
\hline claudication & $14(22.6 \%)$ & $12(15.6 \%)$ & 1.106 & 0.293 \\
\hline rest pain & $25(40.3 \%)$ & $33(42.9 \%)$ & 0.091 & 0.763 \\
\hline gangrene or tissue loss & $23(37.1 \%)$ & $32(41.5 \%)$ & 0.286 & 0.593 \\
\hline
\end{tabular}




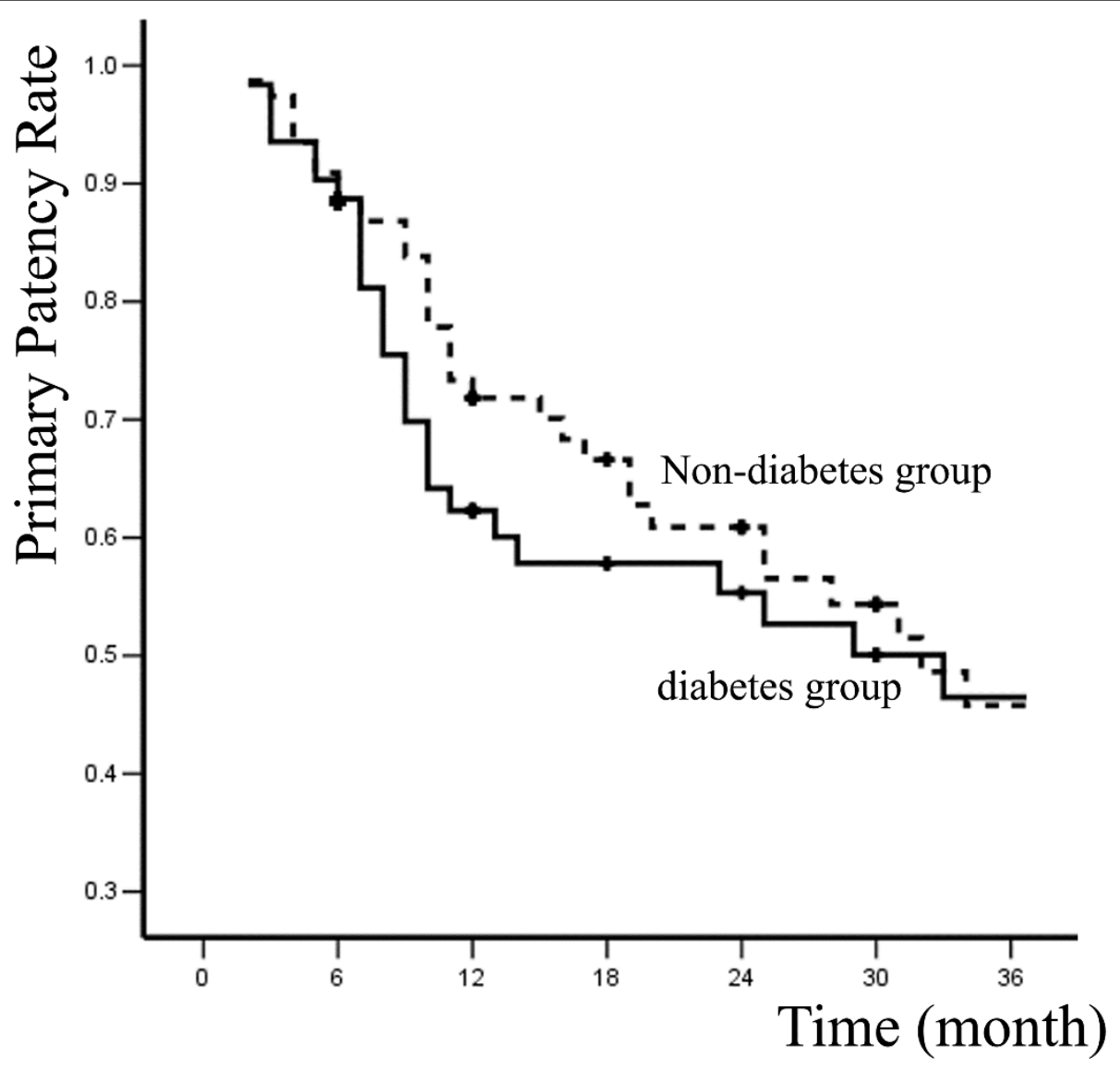

Figure 1 Primary patency rates of two groups.

Perioperative 30-day mortality was $0 \%$. Major complications were access-related and included groin hematoma in $7.2 \%$ patients (all not requiring operative exploration), and pseudoaneurysm formation in $2.2 \%$ patients (successfully treated by local pressure bandaging).

Mean follow-up time for all patients was $26.3 \pm 15.2$ months (6-48 months). 47 patients accepted re-interventional operation after restenosis, with success rate $80.9 \%$ (38/47). The overall rate of percutaneous re-intervention during the follow-up period was $33.8 \%$ (47/139). After failure of percutaneous therapy or restenosis, 21 patients with limb-threat underwent surgical bypass for limb-salvage with success rate $76.2 \%(16 / 21)$, and 19 patients underwent lower extremity major amputation.

\section{Discussion}

\section{Etiology and prognosis}

The hyperglycemia and lipid metabolic abnormality not only lead to injury of the vascular endothelial cells, but also initiate and promote the process of atherosclerosis in diabetes. Some protective cytokines, such as adiponectin and osteoprotegerin, could relieve the progression of PAOD. Adiponectin exhibits anti-inflammatory and atheroprotective actions and osteoprotegerin protects vascular endothelial cells and inhibits atherosclerosis. Lower plasma levels of adiponectin and higher osteoprotegerin were found in diabetic patients with PAOD [9-11]. In fact, the incidence of atherosclerosis in diabetes was significantly higher than that in non-diabetic patients, and the lesion in diabetes was more serious and diffuse. For diabetes, atherosclerosis usually involved the below-knee arteries; the severe vascular lesions and their wide range often lead to less effective intervention; on the other hand, initial hyperplasia or smooth muscle cell proliferation and the progression of atherosclerosis was more serious in diabetes than that in non-diabetes after revascularization.

Patients with PAOD have a poor clinical course. During the first year of diagnosis, mortality is $20 \%-30 \%$, and an equivalent number undergo amputations or suffer from persistent pain [12]. Lower extremity bypass has been applied very successfully even in difficult clinical cases, including the treatment of patients with diabetic foot gangrene and other conditions which carry a high risk of amputation [13]. But bypass surgery can only be 


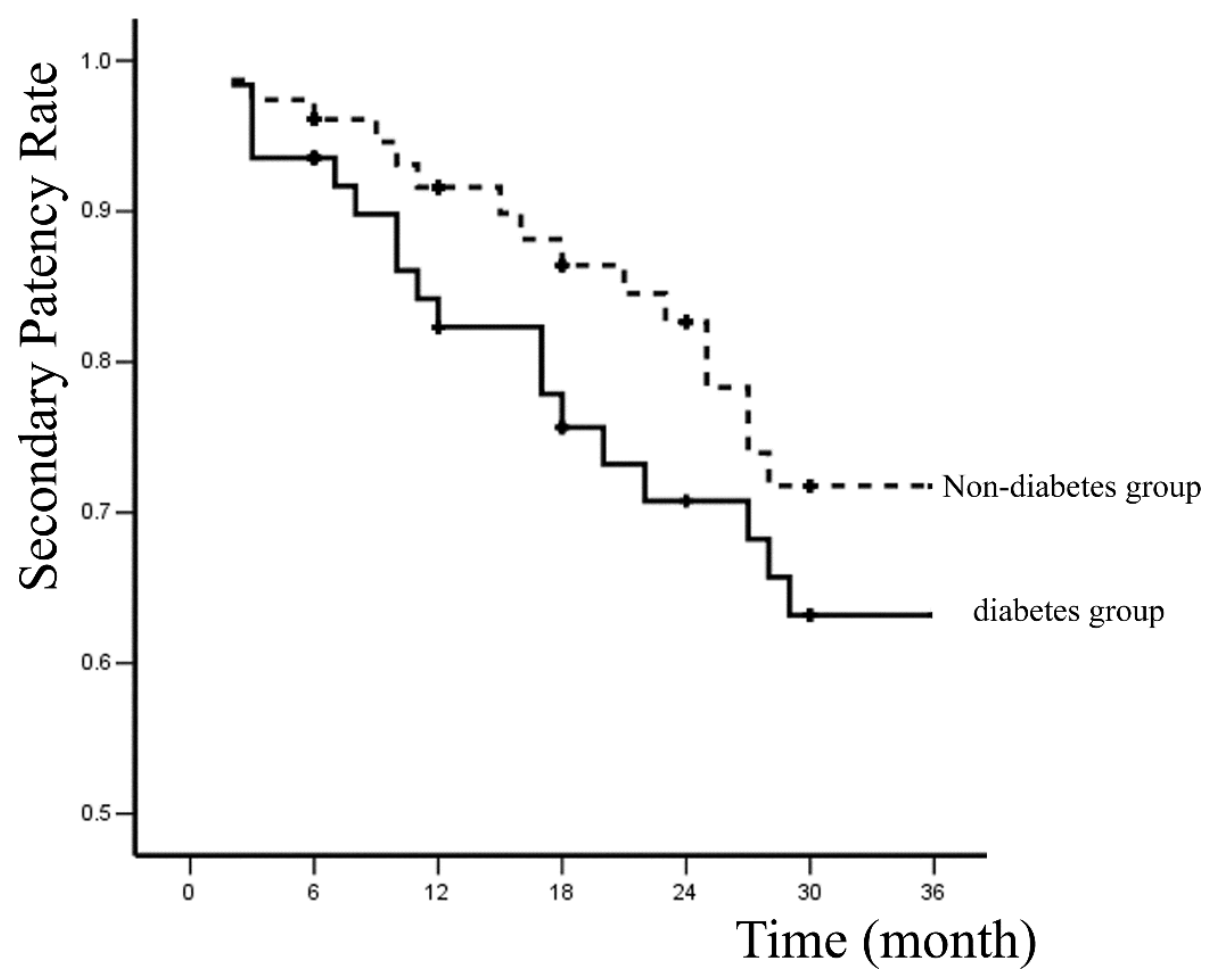

Figure 2 Secondary patency rates of two groups.

performed to a minority of patients because of poor runoff, advanced age, and cardiac co-morbidities. Surgical treatment is often withheld from those patients who would benefit. Surgical complications include death (1.3\%-6\%), myocardial infarction (1.9\%-3.4\%), wound infections (10\%-30\%), leg edema (50\%-100\%), and early graft failure rates $(6 \%-49 \%)$ requiring repeat surgery $[12,14]$.

\section{Therapeutic regimen}

Angioplasty for critical limb ischemia was reported nearly 50 years ago [15]. Hanna et al. [16] reported a $21 \%$ procedural complication rate, including embolization and thrombosis in patients with critical limb ischemia undergoing balloon angioplasty, whereas Dorros et al. [17] demonstrated that PTA of below-knee arteries could be performed with relative safety and with satisfactory results.

The mortality and major morbidity in patients treated for limb-threatening disease with percutaneous interventions was only 0 and $8.1 \%$, respectively, compared with usual mortalities and morbidities of $5 \%$ and $30 \%$ for open surgical bypass [12]. To some extent, it appears that the short-term advantages of minimally invasive vascular therapies are often counterbalanced by diminished durability. Percutaneous therapy for limb-threatening lower extremity vascular disease with or without diabetes has no exception, with primary patency rates at 36 months of $46.5 \%$ and $60.9 \%$. However, secondary patency rates were more reasonable at $65.7 \%$ and $71.8 \%$, and more importantly, limb salvages rates were $81.9 \%$ and $83.1 \%$ at 36 months.

\section{Efficacy of different studies}

It was confirmed that PTA was an effective and safe therapy for short iliac arterial stenosis. But the longterm patency rates of PTA in complicated iliac arterial lesions such as long occlusion were relative low. The 3year primary patency rates in PTA group were lower than $60 \%[18,19]$; whereas primary patency rates in stenting group were up to $90 \%$ [20-22]. Bosch and Hunink [23] reported the technical success rate of interventional therapy for iliac occlusive disease in stent group was higher than that in PTA group, but the difference was not statistically significant. In our study, 1year and 3-year primary patency rate for iliac arterial lesions in diabetes group or non-diabetes group were $87.5 \%, 75.1 \%$ and $86.5 \%, 71.1 \%$, respectively.

Bakken et al. [24] reported the clinical results of interventional therapy for femoral lesions with diabetes was better than that without diabetes. In our study, 1, 3 years primary patency rate for femoral lesions in with or without diabetes group were similar $(73.2 \%, 58.6 \%$ and $80.9 \%, 52.8 \%)$. Role of femoral arterial stents in the 


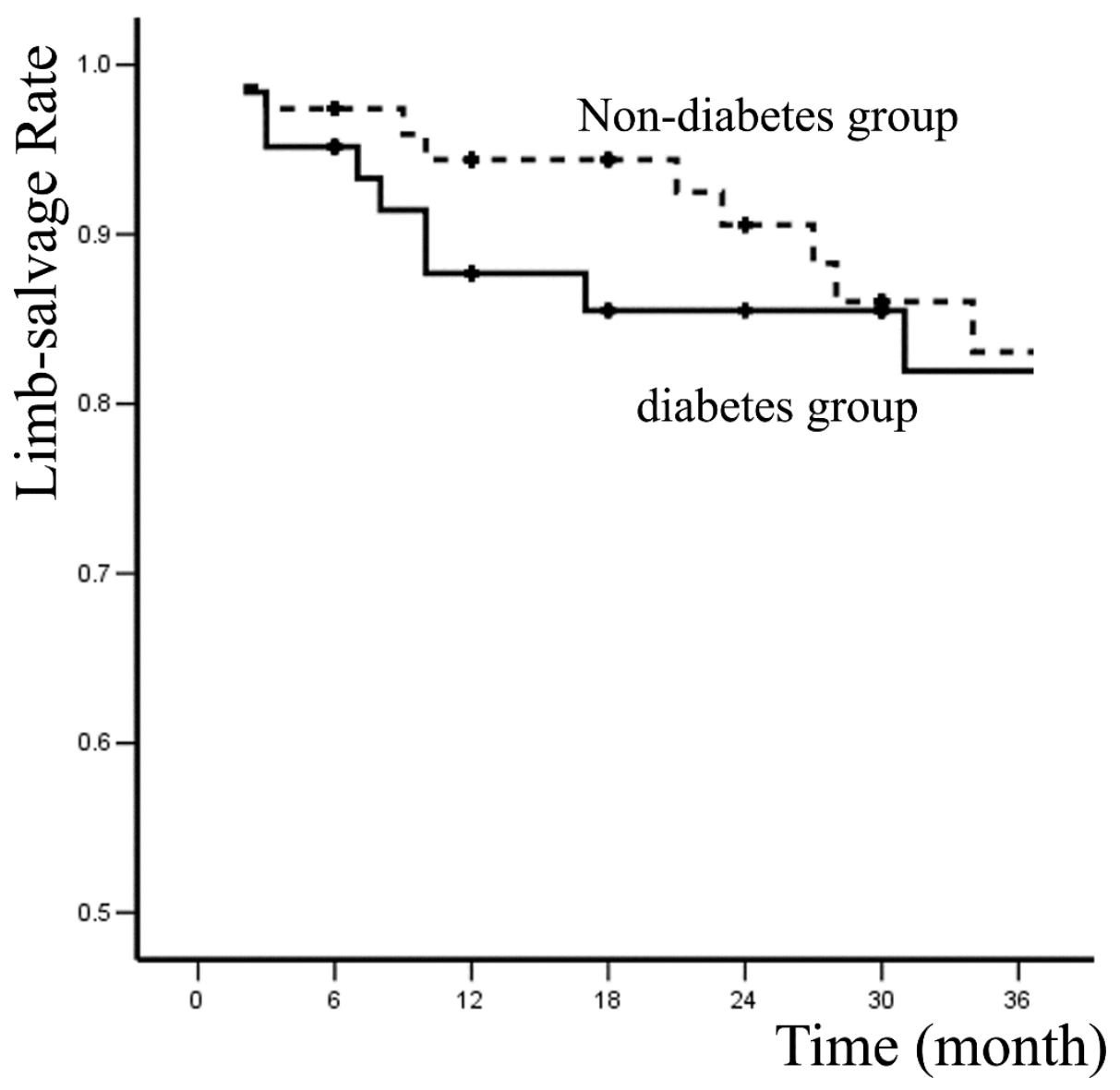

Figure 3 Limb-salvage rates of two groups.

management of PAOD was still controversial. In one meta-analysis [25] which included 452 patients who underwent femoropopliteal PTA and 482 patients who underwent femoropopliteal stenting, the 1-year primary patency rates following PTA ranged from $45 \%$ to $84.2 \%$ and at 2 years it varied from $25 \%$ to $77.2 \%$, the 1 -year primary patency rates in the stent implantation group varing from $63 \%$ to $90 \%$, and 2 -year primary patency ranging from $46 \%$ to $87 \%$. In 73 patients with average 8 $\mathrm{cm}$ long femoral arterial stenosis or occlusion, restenosis rates in the stent and PTA groups were $2.9 \%$ versus
$18.9 \%, 18.2 \%$ versus $50.0 \%$, and $34.4 \%$ versus $61.1 \%$ at 3 , 6 , and 12 months by sonography [26]. Perrio et al. [27] reported 1 year femoral artery primary patency rates were $57 \%$ in stent group and 53\% in PTA group. Kougias et al. [28] reported at 1 year femoral artery primary patency for the subintimal balloon angioplasty and subintimal placement of covered stent groups was $28 \%$ versus $75 \%$, whereas secondary patency was $37 \%$ versus $84 \%$. But in other study undergoing subintimal angioplasty in the femoral and popliteal arteries, one-year primary and secondary patency for stent vs. no-stent group

Table 2 The results of primary, secondary patency rates and limb-salvage rates for all patients

\begin{tabular}{|c|c|c|c|c|c|}
\hline & & 6 months & 12 months & 24 months & 36 months \\
\hline Primary & Diabetic $(n=62)$ & $88.7 \% \pm 4.0 \%$ & $62.3 \% \pm 6.6 \%$ & $55.3 \% \pm 7.0 \%$ & $46.5 \% \pm 7.5 \%$ \\
\hline $\begin{array}{c}\text { patency } \\
\text { rate }\end{array}$ & Non-diabetic $(n=77)$ & $90.9 \% \pm 3.3 \%$ & $71.8 \% \pm 5.4 \%$ & $71.8 \% \pm 5.4 \%$ & $60.9 \% \pm 6.2 \%$ \\
\hline Secondary & Diabetic $(n=62)$ & $93.5 \% \pm 3.1 \%$ & $82.3 \% \pm 5.1 \%$ & $70.8 \% \pm 6.5 \%$ & $65.7 \% \pm 7.0 \%$ \\
\hline $\begin{array}{c}\text { patency } \\
\text { rate }\end{array}$ & Non-diabetic $(n=77)$ & $96.1 \% \pm 2.2 \%$ & $91.6 \% \pm 3.3 \%$ & $82.7 \% \pm 4.8 \%$ & $71.8 \% \pm 6.2 \%$ \\
\hline Limb-salvage & Diabetic $(n=62)$ & $95.2 \% \pm 2.7 \%$ & $87.7 \% \pm 4.4 \%$ & $85.5 \% \pm 4.8 \%$ & $81.9 \% \pm 5.8 \%$ \\
\hline rate & Non-diabetic $(n=77)$ & $97.4 \% \pm 1.8 \%$ & $94.4 \% \pm 2.7 \%$ & $90.6 \% \pm 3.7 \%$ & $83.1 \% \pm 5.4 \%$ \\
\hline
\end{tabular}




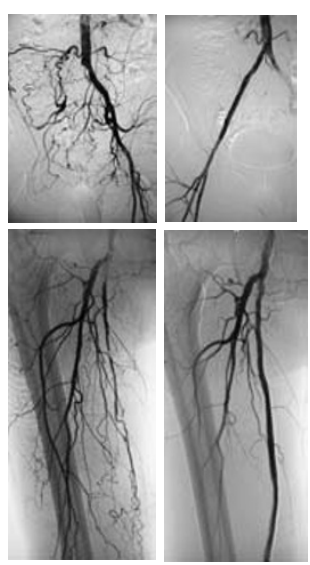

Figure 4 lliaco-femoral arterial long occlusion. (a) DSA displayed right iliac artery overall occlusion; (b) after PTA and stenting, blood flow in right iliac artery was recovered; (c) DSA displayed right superficial femoral artery overall occlusion; (d) after PTA and stenting, blood flow in right superficial femoral artery was recovered.

was $50 \%$ versus $45 \%$ and $70 \%$ versus $78 \%$ [29]. In a contrast study between selective stenting and systematic stenting of femoral artery, Becquemin et al. [30] reported at 1-year follow-up restenosis of the treated site was noted in $32.3 \%$ patients in selective stent group and $34.7 \%$ patients in systematic stent group. After 4 years, limb-salvage rates in selective stent group and in systematic stent group were $57 \%, 44 \%$, respectively. Systematic stenting in femoral artery did not improve long term patency.

The treatment of infra-popliteal arterial occlusive disease was still a clinical puzzle for vascular surgeons and interventional radiologists. The first reason was that
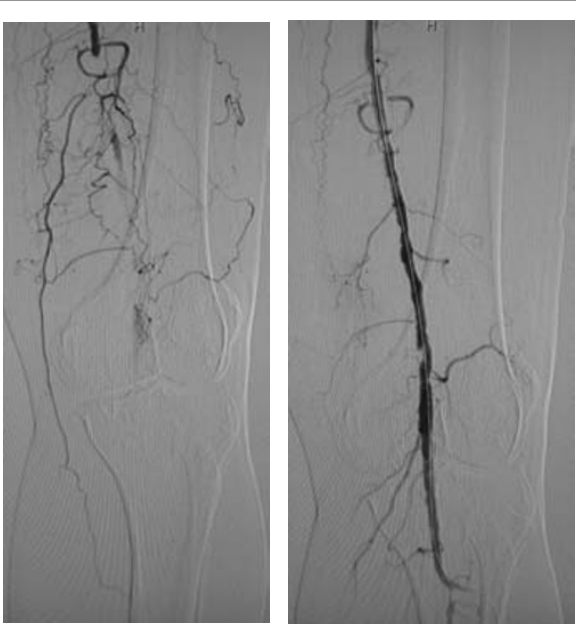

Figure 5 Popliteal arterial long occlusion case. (a) DSA displayed left popliteal artery overall occlusion; (b) after PTA and stenting, blood flow in left popliteal artery was recovered.
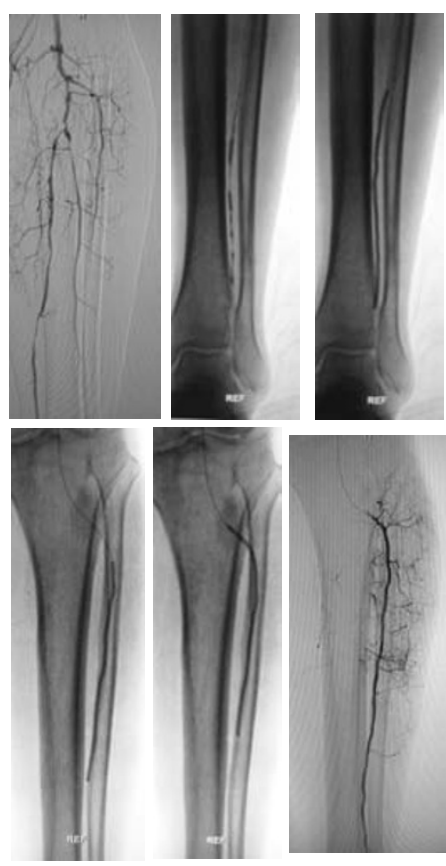

Figure 6 Anterior tibial artery long occlusion case. (a) DSA displayed left anterior tibial artery long occlusion; (b-e) Deep balloon $(2.5 \mathrm{~mm} \times 80 \mathrm{~mm})$ dilated the anterior tibial artery; (f) after PTA, blood flow in left anterior tibial artery was recovered.

infra-popliteal arterial occlusive disease usually comorbided with diabetic arteriosclerosis which have more calcification and more hard plaque. The second reason was that the outflow tract of infra-popliteal artery has higher resistance. In a meta analysis, Romiti et al. [31] reported the immediate technique success rate of PTA in infrapopliteal arterial occlusive disease was $89 \%$. After 12 and 36 months primary patency rates, secondary patency rates, and limb salvage rates were $77.4 \%$ and $48.6 \%, 83.3 \%$ and $62.9 \%, 93.4 \%$ and $82.4 \%$, respectively. Lejay et al. [32] reported at 1 year the infra-popliteal arteries primary patency rates and limb salvage rates for PTA were $60 \%$ and $85 \%$, respectively. In a contrast study between PTA and atherectomy of infra-popliteal arterial occlusive disease, Semaan et al. [33] reported primary patency of the popliteal artery at 12 months were $75 \%$ and $73 \%$, respectively, but the difference was not statistically significant. In our study, 6, 12 months primary patency rate for tibial arterial lesions with or without diabetes were $75 \%, 53.8 \%$ and $73.7 \%$, 55.3\%. The result was lower than the result in literature. 26 patients $(26 / 35)$ in the study comorbided with proximal arterial occlusive lesions may be the origin.

\section{Limitations}

This was a single-center, consecutive patient trial. ABIs were obtained before intervention to evaluate 


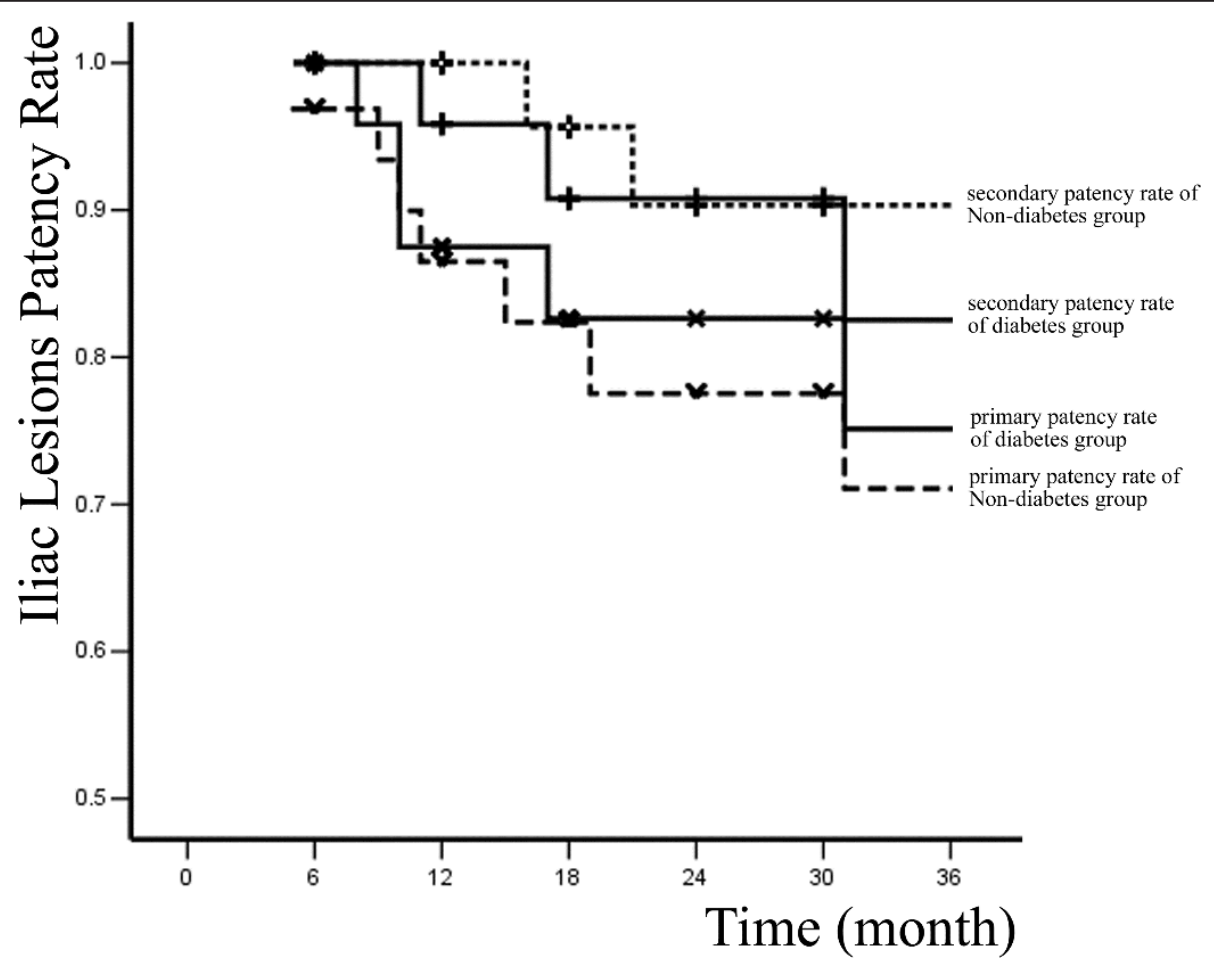

Figure 7 Primary, secondary patency rates for iliac lesions in two groups

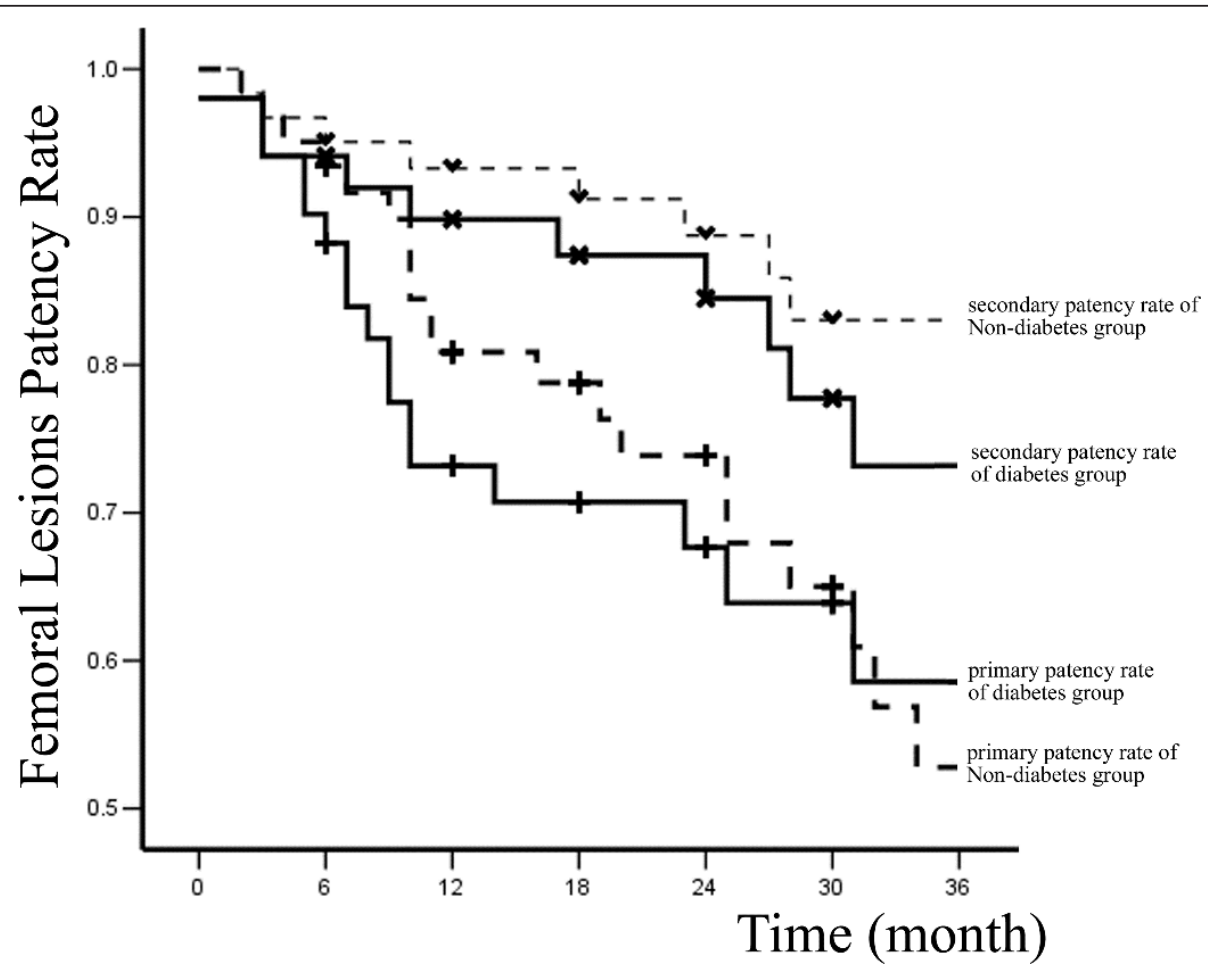

Figure 8 Primary, secondary patency rates for femoral lesions in two groups. 


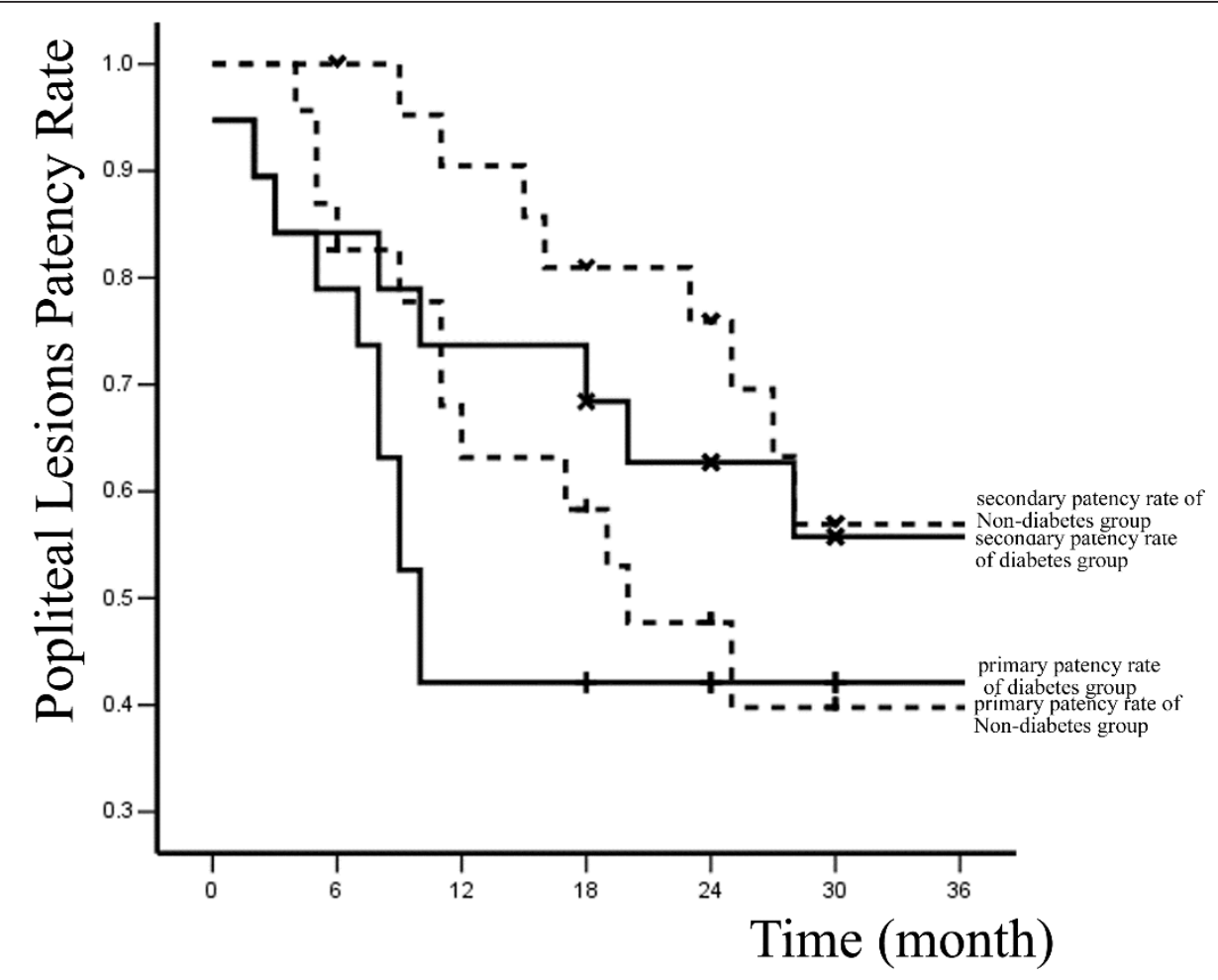

Figure 9 Primary, secondary patency rates for popliteal lesions in two groups

hemodynamic impairment and at one week after intervention to measure improvement. $A B I$ value responded objectively to the status of blood supply in lower extremity, but the mickle factors influenced its magnitude. In the condition of profuse collateral circulation in lower extremity, ABI value could exactly respond to the extent of vascular flow in treated position. The sample number of this study is relative deficient, and subgroups divided

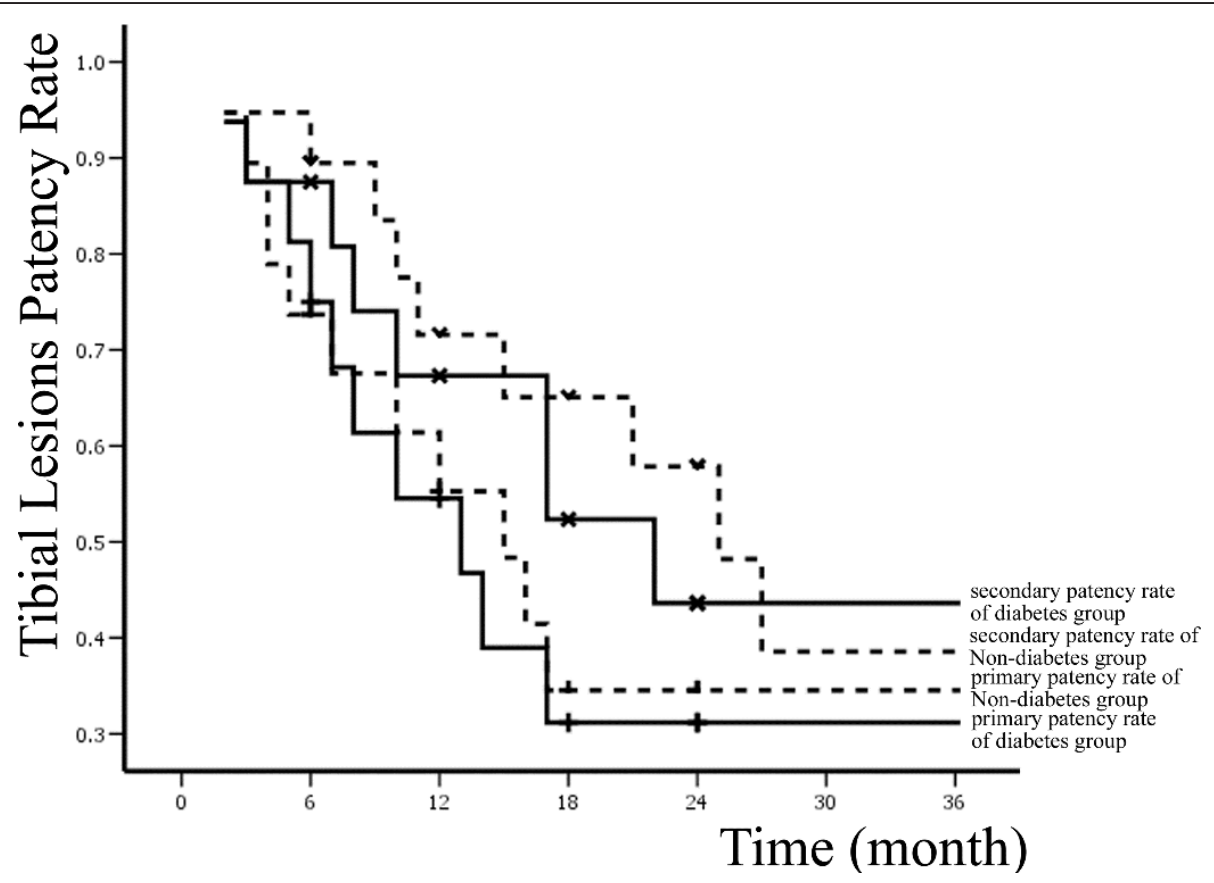

Figure 10 Primary, secondary patency rates for tibial lesions in two groups. 
Table 3 The results of primary and secondary patency rates for different lesions in diabetes group

\begin{tabular}{|c|c|c|c|c|c|}
\hline & & 6 months & 12 months & 24 months & 36 months \\
\hline \multirow[t]{2}{*}{ iliac lesions ( $n=26$ ) } & primary patency rate & $100 \%$ & $87.5 \% \pm 6.8 \%$ & $82.6 \% \pm 7.9 \%$ & $75.1 \% \pm 10.2 \%$ \\
\hline & secondary patency rate & $100 \%$ & $95.8 \% \pm 4.1 \%$ & $90.8 \% \pm 6.2 \%$ & $82.5 \% \pm 9.7 \%$ \\
\hline femoral & primary patency rate & $88.2 \% \pm 4.5 \%$ & $73.2 \% \pm 6.4 \%$ & $67.7 \% \pm 7 \%$ & $58.6 \% \pm 8.6 \%$ \\
\hline $\begin{array}{l}\text { lesions } \\
(n=51)\end{array}$ & secondary patency rate & $94.1 \% \pm 3.3 \%$ & $89.8 \% \pm 4.3 \%$ & $84.5 \% \pm 5.5 \%$ & $73.2 \% \pm 7.8 \%$ \\
\hline popliteal & primary patency rate & $78.9 \% \pm 9.4 \%$ & $42.1 \% \pm 11.3 \%$ & $42.1 \% \pm 11.3 \%$ & $42.1 \% \pm 11.3 \%$ \\
\hline $\begin{array}{l}\text { lesions } \\
(\mathrm{n}=19)\end{array}$ & secondary patency rate & $84.2 \% \pm 8.4 \%$ & $73.7 \% \pm 10.1 \%$ & $62.7 \% \pm 11.2 \%$ & $55.8 \% \pm 11.9 \%$ \\
\hline tibial & primary patency rate & $75.0 \% \pm 10.8 \%$ & $53.8 \% \pm 12.9 \%$ & $30.8 \% \pm 12.5 \%$ & $30.8 \% \pm 12.5 \%$ \\
\hline $\begin{array}{l}\text { lesions } \\
(n=16)\end{array}$ & secondary patency rate & $87.5 \% \pm 8.3 \%$ & $67.3 \% \pm 12 \%$ & $43.6 \% \pm 13.6 \%$ & $43.6 \% \pm 13.6 \%$ \\
\hline
\end{tabular}

Table 4 The results of primary and secondary patency rates for different lesions in non-diabetes group

\begin{tabular}{|c|c|c|c|c|c|}
\hline & & 6 months & 12 months & 24 months & 36 months \\
\hline \multirow[t]{2}{*}{ iliac lesions ( $n=32$ ) } & primary patency rate & $96.9 \% \pm 3.1 \%$ & $86.5 \% \pm 6.3 \%$ & $77.5 \% \pm 8.3 \%$ & $71.1 \% \pm 9.8 \%$ \\
\hline & secondary patency rate & $100 \% \pm 0 \%$ & $100 \% \pm 0 \%$ & $90.3 \% \pm 6.5 \%$ & $83 \% \pm 5.7 \%$ \\
\hline femoral lesions & primary patency rate & $93.4 \% \pm 3.2 \%$ & $80.9 \% \pm 5.2 \%$ & $73.9 \% \pm 6.1 \%$ & $52.8 \% \pm 8.6 \%$ \\
\hline$(n=61)$ & secondary patency rate & $95.1 \% \pm 2.8 \%$ & $93.3 \% \pm 3.2 \%$ & $88.7 \% \pm 4.4 \%$ & $83 \% \pm 5.7 \%$ \\
\hline popliteal & primary patency rate & $82.6 \% \pm 7.9 \%$ & $63.2 \% \pm 10.4 \%$ & $47.7 \% \pm 11.1 \%$ & $39.8 \% \pm 11.7 \%$ \\
\hline $\begin{array}{l}\text { lesions } \\
(n=23)\end{array}$ & secondary patency rate & $100 \% \pm 0 \%$ & $90.5 \% \pm 6.4 \%$ & $75.9 \% \pm 9.4 \%$ & $56.9 \% \pm 11.8 \%$ \\
\hline tibial & primary patency rate & $73.7 \% \pm 10.1 \%$ & $55.3 \% \pm 11.9 \%$ & $34.5 \% \pm 12 \%$ & $34.5 \% \pm 12 \%$ \\
\hline $\begin{array}{l}\text { lesions } \\
(n=19)\end{array}$ & secondary patency rate & $89.5 \% \pm 7 \%$ & $71.6 \% \pm 10.8 \%$ & $57.8 \% \pm 12.4 \%$ & $38.6 \% \pm 13.9 \%$ \\
\hline
\end{tabular}

by distinct lesions position had not enough information for contrasting with literature. As the follow-up period was relative short, this study could not illuminate the long term patency of interventional therapy for PAOD.

\section{Conclusion}

Percutaneous revascularization has rapidly emerged as an alternative to open surgical bypass for patients with chronic lower extremity ischemia. In this study, the good short-term patency rate of percutaneous intervention makes $81.9 \%$ diabetic PAOD patients and $83.1 \%$ non-diabetic PAOD patients keep the limb within three years. With a low risk of morbidity and mortality, the percutaneous revascularization accepted by patients does not affect ultimate necessary surgical revascularization and consequently should be considered as the preferred therapy for chronic lower extremity ischemia. The efficacy and prognosis of interventional therapy in diabetic patients is similar that in non-diabetic patients.

\section{Abbreviations}

PAOD: Peripheral arterial occlusive disease; ABI: Ankle brachial indexes; 3DCTA: Three dimensional computed tomography angiography; PTA: Percutaneous transluminal angioplasty; SPSS: Statistical Package for Social Sciences.

\section{Acknowledgements}

This article was supported by research grants from the Scientific Research Fund of Liaoning Science and Technology Agency, China (No. $2008225010-$ 5) and the Scientific Research Fund of Liaoning Education Agency, China (No. 2007T183) and the Scientific Research Fund of First Hospital of CMU (No. FSFH1006).

\section{Author details}

'Department of Radiology, the First Hospital of China Medical University, 155\# Nanjing North Road, Shenyang 110001, Liaoning, People's Republic of China. ${ }^{2}$ Department of Mathematics, College of Basic Medical Science, China Medical University, 92\# Bei-er Road, Shenyang 110001, Liaoning, People's Republic of China.

\section{Authors' contributions}

LX conceived of the study, and participated in its design and coordination, carried out the clinical studies and helped to draft the manuscript. D-sH participated in the design of the study and performed the statistical analysis. J-jT carried out the clinical studies and drafted the manuscript. JS carried out the clinical studies and drafted the manuscript. All authors read and approved the final manuscript.

\section{Competing interests}

This article was supported by research grants from the Scientific Research Fund of Liaoning Science and Technology Agency, China (No. $2008225010-$ 5) and the Scientific Research Fund of Liaoning Education Agency, China (No. 2007T183) and the Scientific Research Fund of First Hospital of CMU (No. FSFH1006).

The authors have not signed an agreement with any sponsor of the study reported in this article that has a clause which prevents us from publishing both positive and negative results, from collaborating with other investigators to pool data across sites, or that forbids us from publishing without the approval of the sponsor.

The authors declare that they have no competing interests. 
Received: 16 January 2012 Accepted: 28 February 2012

Published: 28 February 2012

\section{References}

1. Eschwege $E$, Simon D, Balkau B: The growing burden of diabetes in the world population. International Diabetes Federation Bulletin 1997, 42:14-19.

2. Jude EB, Oyibo SO, Chalmers N, Boulton AJ: Peripheral arterial disease in diabetic and nondiabetic patients: a comparison of severity and outcome. Diabetes Care 2001, 24:1433-1437.

3. Derubertis BG, Pierce M, Ryer EJ, Trocciola S, Kent KC, Faries PL: Reduced primary patency rate in diabetic patients after percutaneous intervention results from more frequent presentation with limbthreatening ischemia. J Vasc Surg 2008, 47:101-108.

4. Micari A, Vadalà G, Biamino G: Update on the TURBO BOOSTER spectranetics laser for lower extremity occlusive disease. J Cardiovasc Surg (Torino) 2010, 51:233-243.

5. Diehm NA, Hoppe H, Do DD: Drug eluting balloons. Tech Vasc Interv Radiol 2010, 13:59-63.

6. Bosiers M, Peeters P, D'Archambeau O, Hendriks J, Pilger E, Düber C, Zeller T, Gussmann A, Lohle PN, Minar E, Scheinert D, Hausegger K, Schulte KL, Verbist J, Deloose K, Lammer J: AMS INSIGHT Investigators. AMS INSIGHT-absorbable metal stent implantation for treatment of below-the-knee critical limb ischemia: 6-month analysis. Cardiovasc Intervent Radiol 2009, 32:424-435.

7. Jahnke T, Mueller-Huelsbeck S, Charalambous N, Trentmann J, Jamili A, Huemme TH, Bolte $H$, Heller M, Schaefer PJ: Prospective, randomized single-center trial to compare cryoplasty versus conventional angioplasty in the popliteal artery: midterm results of the COLD study. $J$ Vasc Interv Radiol 2010, 21:186-194.

8. Zeller T, Krankenberg H, Steinkamp H, Rastan A, Sixt S, Schmidt A, Sievert H, Minar E, Bosiers M, Peeters P, Balzer JO, Gray W, Tübler T, Wissgott C, Schwarzwälder $U$, Scheinert D: One-year outcome of percutaneous rotational atherectomy with aspiration in infrainguinal peripheral arterial occlusive disease: the multicenter pathway PVD trial. J Endovasc Ther 2009, 16:653-662.

9. Tuttolomondo A, La Placa S, Di Raimondo D, Bellia C, Caruso A, Lo Sasso B, Guercio G, Diana G, Ciaccio M, Licata G, Pinto A: Adiponectin, resistin and IL-6 plasma levels in subjects with diabetic foot and possible correlations with clinical variables and cardiovascular co-morbidity. Cardiovasc Diabetol 2010, 9:50

10. Ho DY, Cook NR, Britton KA, Kim E, Creager MA, Ridker PM, Pradhan AD: High-molecular-weight and total adiponectin levels and incident symptomatic peripheral artery disease in women: a prospective investigation. Circulation 2011, 124:2303-2311.

11. Poulsen MK, Nybo M, Dahl J, Hosbond S, Poulsen TS, Johansen A, HøilundCarlsen PF, Beck-Nielsen H, Rasmussen LM, Henriksen JE: Plasma osteoprotegerin is related to carotid and peripheral arterial disease, but not to myocardial ischemia in type 2 diabetes mellitus. Cardiovasc Diabetol 2011, 10:76.

12. Dormandy JA, Rutherford RB: Management of peripheral arterial disease (PAD). TASC working group. transatlantic inter-society consensus (TASC). J VasC Surg 2000, 31:S1-S296.

13. Muluk SC, Muluk VS, Kelley ME, Whittle JC, Tierney JA, Webster MW, Makaroun MS: Outcome events in patients with claudication: a 15 year study in 2,777 patients. J Vasc Surg 2001, 33:251-258.

14. Dietzek AM, Gupta SK, Kram HB, Wengerter KR, Veith FJ: Limb loss with patent infra-inguinal bypasses. Eur J Vasc Surg 1990, 4:413-417.

15. Hall KV: The great saphenous vein used in-situ as an arterial shunt after extirpation of vein valves. Surgery 1962, 51:492-499.

16. Hanna GP, Fujise K, Kjellgren O, Feld S, Fife C, Schroth G, Clanton T, Anderson V, Smalling RW: Infrapopliteal transcatheter interventions for limb salvage in diabetic patients: importance of aggressive interventional approach and role of transcutaneous oximetry. J Am Coll Cardiol 1997, 30:664-669.

17. Dorros G, Jaff MR, Dorros AM, Mathiak LM, He T: Tibioperoneal (outflow lesion) angioplasty can be used as primary treatment in 235 patients with critical limb ischemia: five year follow-up. Circulation 2001, 104:2057-2062

18. Kudo T, Chandra FA, Ahn SS: The effectiveness of percutaneous transluminal angioplasty for the treatment of critical limb ischemia: a 10-year experience. J Vasc Surg 2005, 41:423-435.
19. Kudo T, Chandra FA, Ahn SS: Long-term outcomes and predictors of iliac angioplasty with selective stenting. J Vasc Surg 2005, 42:466-475.

20. Gandini R, Fabiano S, Chiocchi M, Chiappa R, Simonetti G: Percutaneous treatment in iliac artery occlusion: long-term results. Cardiovasc Intervent Radiol 2008, 31:1069-1076.

21. Park KB, Do YS, Kim DI, Kim DK, Kim YW, Shin SW, Cho SK, Choo SW, Choe $\mathrm{YH}$, Choo IW: The transatlantic intersociety consensus (TASC) classification system in iliac arterial stent placement: long-term patency and clinical limitations. J Vasc Interv Radio/ 2007, 18:193-201.

22. AbuRahma AF, Hayes JD, Flaherty SK, Peery W: Primary iliac stenting versus transluminal angioplasty with selective stenting. J Vasc Surg 2007, 46:965-970.

23. Bosch $J$, Hunink MG: Meta-analysis of the results of percutaneous transluminal angioplasty and stent placement for aortoiliac occlusive disease. Radiology 1997, 204:87-96.

24. Bakken AM, Palchik E, Hart JP, Rhodes JM, Saad WE, Davies MG: Impact of diabetes mellitus on outcomes of superficial femoral artery endoluminal interventions. J Vasc Surg 2007, 46:946-958.

25. Mwipatayi BP, Hockings A, Hofmann M, Garbowski M, Sieunarine K: Balloon angioplasty compared with stenting for treatment of femoropopliteal occlusive disease: a meta-analysis. J Vasc Surg 2008, 47:461-469.

26. Dick P, Wallner H, Sabeti S, Loewe C, Mlekusch W, Lammer J, Koppensteiner R, Minar E, Schillinger M: Balloon angioplasty versus stenting with nitinol stents in intermediate length superficial femoral artery lesions. Catheter Cardiovasc Interv 2009, 74:1090-1095.

27. Perrio S, Holt PJ, Patterson BO, Hinchliffe RJ, Loftus IM, Thompson MM: Role of superficial femoral artery stents in the management of arterial occlusive disease: review of current evidence. Vascular 2010, 18:82-92.

28. Kougias P, Chen A, Cagiannos C, Bechara CF, Huynh TT, Lin PH: Subintimal placement of covered stent versus subintimal balloon angioplasty in the treatment of long-segment superficial femoral artery occlusion. Am J Surg 2009, 198:645-649.

29. Schmieder GC, Richardson Al, Scott EC, Stokes GK, Meier GH, Panneton JM Selective stenting in subintimal angioplasty: analysis of primary stent outcomes. J Vasc Surg 2008, 48:1175-1180.

30. Becquemin JP, Favre JP, Marzelle J, Nemoz C, Corsin C, Leizorovicz A: Systematic versus selective stent placement after superficial femoral artery balloon angioplasty: a multicenter prospective randomized study. J Vasc Surg 2003, 37:487-494.

31. Romiti M, Albers M, Brochado-Neto FC, Durazzo AE, Pereira CA, De Luccia N: Meta-analysis of infrapopliteal angioplasty for chronic critical limb ischemia. J Vasc Surg 2008, 47:975-981.

32. Lejay A, Georg Y, Bajcz C, Thaveau F, Geny B, Kretz JG, Chakfé N: Endovascular treatment of infra-popliteal arteries in patients with critical limb ischemia. Acta Chir Belg 2009, 109:684-693.

33. Semaan E, Hamburg N, Nasr W, Shaw P, Eberhardt R, Woodson J, Doros G, Rybin D, Farber A: Endovascular management of the popliteal artery: comparison of atherectomy and angioplasty. Vasc Endovascular Surg 2010, 44:25-31.

doi:10.1186/1475-2840-11-17

Cite this article as: Xiao et al:: Efficacy of endoluminal interventional therapy in diabetic peripheral arterial occlusive disease: a retrospective trial. Cardiovascular Diabetology 2012 11:17.

\section{Submit your next manuscript to BioMed Central and take full advantage of:}

- Convenient online submission

- Thorough peer review

- No space constraints or color figure charges

- Immediate publication on acceptance

- Inclusion in PubMed, CAS, Scopus and Google Scholar

- Research which is freely available for redistribution

Submit your manuscript at www.biomedcentral.com/submit
C Biomed Central 